\title{
LXIX. On the hydrates of nitric acid
}

\section{Mr. Arthur Smith}

To cite this article: Mr. Arthur Smith (1847) LXIX. On the hydrates of nitric acid, Philosophical Magazine Series 3, 31:210, 454-459, DOI: 10.1080/14786444708645891

To link to this article: http://dx.doi.org/10.1080/14786444708645891

\section{Published online: 30 Apr 2009.}

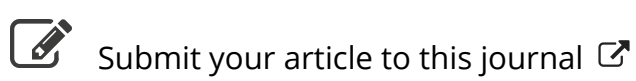

LII Article views: 2

Q View related articles 두 
As the sun descends beneath the horizon, the neutral point of $\mathbf{M}$. Arago separates from the antisolar point, and when this point is first seen in the morning before sunrise, its distance from the antisolar point is a maximum; it gradually approaches that point till the sun rises, and also till the neutral point itself reaches the horizon, when its distance from the antisolar point is a minimum.

When the altitude of the sun is $45^{\circ}$, the distance $x$ of the neutral point above the sun is about $13^{\circ} 5^{\prime}$, and the distance $x^{\prime}$ of the neutral point below the sun $6^{\circ} 42^{\prime} ;$ at other altitudes we have

and

$$
\begin{aligned}
& x=\Delta \cos A, \\
& x^{\prime}=\frac{\Delta \cos A,}{\tan Z,}
\end{aligned}
$$

$\Delta$ being $18 \frac{1}{2}^{\circ}, \mathrm{A}$ the sun's altitude, and $\mathrm{Z}$ the zenith distance of $\mathrm{P}^{\prime}$, the neutral point below the sun.

An interesting paper, entitled Delle Leggi della Polarizzazione della Luce Solare nella Atmosphera Serena, communicato con lettera al David Brewster, LL.D., F.R.S., Lond. et Edin., membro delle Principali Academie di Europa, del Prof. A. B. Francesco Zantedeschi, will be found in the Raccolta Fisico-chimica Italiana, tom. i. fascic. 10. 1846. The details in this paper are chiefly historical. The results obtained by M. Zantedeschi himself, which are of a general nature, differ in several respects from mine; but whether this difference arises from a difference in the methods of observation, or from the different states of the atmosphere under which the observations were made, $I$ an not able to determine.

In a Memoir on the Polarization of the Atmosphere, which, I trust, will soon be published in the Transactions of the Royal Irish Academy, I shall give a full account of my observations, and enter more deeply into the subject than would have been proper in the preceding popular explanation of a Map of the Lines of Equal Polarization.

LXIX. On the Hydrates of Nitric Acid. By Mr. ArThur Sмгтн, Assistant in the Laboratory of University College, London*.

GOME doubt still hanging over the composition of the hy$D$ drates of nitric acid, especially of the first hydrate, I was induced to try some experiments with a view of diminishing this uncertainty. For this purpose a quantity of the red fuming acid was procured, which I exarnined before com* Communicated by the Chemical Society; having been read June 7 , 1847. 
mencing my experiments very carefully for chlorine, and found to be perfectly free from that impurity, and to have a specific gravity of 1.500 .

Fourteen ounces of acid of the above-named strength were mixed with 7 ounces of commercial oil of vitriol, and distilled in a sand-bath over a gas flame; the first 2 ounces that came over were rejected, and the receiver changed directly the red fumes of nitrous acid were observed to fill the interior of the retort. The acid collected was almost as dark in colour as the acid before distillation. Its specific gravity was 1.522 , and it turned out to be perfectly free from the smallest trace of sulphuric acid.

I also examined the first two ounces of acid that came over very carefully for chlorine, and found it to contain scarcely a trace, nitrate of silver producing only a slight opalescence, and that which came over afterwards, being the portion that I selected for my experiments, contained none at all. This last acid, when diluted with water, gave off nitric oxide gas with a burst of effervescence, which was the principal reason why it could not be employed to ascertain the exact amount of real acid by saturation in its present dark-coloured condition.

The apparatus employed in decolorizing the nitric acid consisted of a capacious retort, capable of holding about a pint, to the beak of which was attached a large tubulated receiver, which was kept surrounded with water, to condense any little acid that might come over during the process; to the tubulure of this receiver was adapted a glass tube, bent at right angles, fitting tightly with a cork, the other extremity being in connexion with a large gas-holder, which was kept constantly filled with water, to be used as an aspirator. To the tubulure of the retort was also fitted a long glass tube bent at right angles, the one end of which terminated within an inch of its bottom, whilst the other was in connexion with a couple of tubes, each 2 feet 11 inches long, arranged side by side, and connected by means of a tube of a smaller diameter bent like the letter $U$.

These long tubes, through which the air was to be aspired, were filled, the one with dried chloride of calcium, and the other with pumice-stone moistened with oil of vitriol, and by these means the absence of all moisture from the air was ensured.

In decolorizing the acid a quantity amounting to 6 or 7 ounces was introduced into the retort, and after having ascertained that the whole apparatus was perfectly tight, heat was applied to the bottom of a small sand-bath in which the retort was immersed, and the temperature kept up carefully to $170^{\circ} \mathrm{F}$. Then, by removing the plug at the bottom of the 
gas-holder, and turning the stop-cock at the top, which was in connexion with the apparatus, a constant flow of perfectly dry air was caused to bubble through the nitric acid in the retort, the level of which was kept 2 or 3 inches above the orifice of the tube in the interior, the only passage for the air being through the long desiccating tubes. Aspiration kept up for two or three hours was found to be generally sufficient to decolorize completely 6 or 7 ounces of nitric acid.

The acid before decolorization had a specific gravity of 1.522, and after the process fell to 1.503. Fifty grs. of the colourless nitric acid were accurately weighed out in a stoppered specific gravity bottle, to which was cautiously added, whilst in the bottle, with a view to prevent any loss from splashing, a known weight of perfectly pure carbonate of soda, recently ignited in a porcelain crucible, until the solution was perfectly neutral to test-paper. The absence of any sulphate or chloride in the carbonate had been previously ascertained.

I. Carbonate of soda required $40 \cdot 23$ grs.

II. Carbonate of soda required $40 \cdot 23$ grs.

The quantity of carbonate of soda that 50 grs. of acid required for saturation, then, was $40 \cdot 23$ grs., which corresponds to 40.78 grs. of nitric acid, or 81.56 per cent.

An acid containing $1 \frac{1}{2}$ equiv. of water would contain in 100 parts-

$$
\begin{aligned}
& \text { Real nitric acid . . . } 80 \\
& \text { Water . . . . } \cdot \frac{20}{100}
\end{aligned}
$$

A portion of the prepared acid, amounting to about 5 ounces, was introduced into a small retort, through the tubulure of which was fitted tightly, by means of a stopping of moist clay, a delicate thermometer, which was kept immersed in the liquid. The acid began to boil at $190^{\circ}$, and before the distillation had come to an end it had risen to $250^{\circ}$. The acid coming over between $190^{\circ}$ and $200^{\circ}$ was collected apart to be examined by saturation.

$50 \mathrm{grs}$. of the acid which remained in the retort boiling at $250^{\circ}$ were then examined, and found to require $31 \cdot 20 \mathrm{grs}$. of carbonate of soda in the first experiment, and 31.07 in the second, for saturation; the mean of the two experiments would correspond to 63.11 per cent. of nitric acid.

50 grs. of the most volatile portion, namely, that which came over between the temperatures of $190^{\circ}$ and $200^{\circ}$, were then weighed out exactly; this quantity was found to require no less than 41.92 grs. in the first experiment, and 41.91 in the second, corresponding to 84.96 per cent. nitric acid; but then it must be remembered that this acid had a very dark red colour. 
A quantity of this red acid was introduced into the decolorizing apparatus, and a constant rapid stream of dry air made to bubble through it for two hours; at the expiration of that time it was found to be perfectly limpid, and colourless as water, and to have a specific gravity of 1.516 at $60^{\circ}$.

50 grs. of the last acid were weighed out and neutralized with pure carbonate of soda as before. The numbers below will show the amount required for saturation :-

$$
\begin{aligned}
& \text { Exp. Carb. of soda. Mean. } \\
& \text { 1. . } 41 \cdot 77 \\
& \text { 3. . . 41.64 } 4\} 84 \cdot 54 \text { per cent. nitric acid. }
\end{aligned}
$$

This acid began to boil at about $184^{\circ}$, the greater part distilling over between the temperatures of $184^{\circ}$ and $188^{\circ}$; it afterwards rose when near the end to $200^{\circ}$.

The first portion that came over was collected apart, introduced into the decolorizing apparatus, and dry air again drawn through it until it was quite colourless. This was found to be necessary after each distillation, on account of the decomposition that it suffered upon boiling, which rendered it as dark in colour as the original acid. $50 \mathrm{grs}$. of the colourless acid, of the specific gravity of 1.517 at $60^{\circ}$, were weighed out, and carbonate of soda very carefully added until neutral to test-paper. The increase in the specific gravity this time only amounted to 001 .

$$
\left.\begin{array}{l}
\text { Exp. Carb. of soda. Acid. Mean. } \\
\left.\begin{array}{l}
1 . .41 \cdot 79=42 \cdot 36 \\
2 .
\end{array}\right\} 41 \cdot 81=42 \cdot 38
\end{array}\right\} 42 \cdot 37 .
$$

Hence in 100 parts-

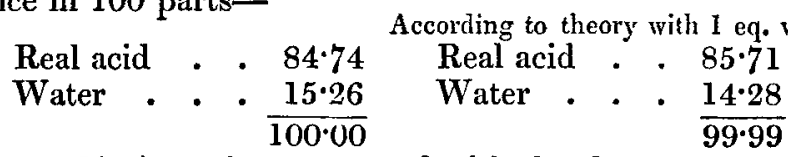

This would give, when compared with the theoretical composition of nitric acid with 1 equiv. of water, a deficiency of $\cdot 97$ in the acid, and an excess of $\cdot 98$ in the water.

This hydrate, when pure, was a perfectly limpid and colourless liquid, like so much water; it boiled at $184^{\circ}$, and had a specific gravity of 1.517 at $60^{\circ}$. It was found not to have the slightest action on tin or iron even when boiled. A portion of this acid placed in a freezing mixture composed of ice and salt suffered no change.

These experiments leave little doubt concerning the composition of the first hydrate of nitric acid, namely, that it is the true mono-hydrate, consisting of 1 equiv. of nitric acid and $\mathrm{l}$ of water, $\mathrm{HO}, \mathrm{NO}_{5}$.

Deuto-Hydrate.-In preparing this hydrate, I set out by obtaining a quantity of colourless strong nitric acid, the exact 
amount of real acid in which was ascertained by saturation to be 79.79 per cent. To reduce this acid to the proper strength, so as to contain exactly 2 equivs. of water, it was found by calculation that it would require 63.86 grs. of water to every 1000 grs. of acid.

The proper proportions of acid and water were weighed out carefully in a stoppered specific gravity bottle, and the two mixed. This mixture was cooled down to $60^{\circ}$ and found to have the sp. gr. $1 \cdot 486$.

50 grs. of this hydrate were weighed out and saturated in the usual way with recently-ignited carbonate of soda. The quantities of carbonate of soda required were as follows :-

Exp. Carb. of soda. Mean.

$$
\left.\begin{array}{l}
\text { 1. . . 37.45 } \\
2.57
\end{array}\right\} 37 \cdot 49 \text {, or } 74 \cdot 98 \text { per cent. acid. }
$$

An acid containing 2 equivs. of water will contain 75 per cent. real acid.

A portion of this acid was introduced into a small retort and distilled. It began to boil, as nearly as could be judged, at about $200^{\circ}$, it being difficult to come at the exact temperature on account of the very rapid rise of the thermometer, which continued to take place until it had gained the temperature of $218^{\circ}$; it afterwards rose when near the end to $250^{\circ}$.

It appears, then, from these experiments, that no such thing as a deuto-hydrate exists, but that when a mixture is made in the proportions to form such a hydrate and subjected to distillation, it divides spontaneously into the first and another, at the same time suffering considerable decomposition; and the acid which is found remaining in the retort has the exact boiling-point of the tetra-hydrate, namely, $250^{\circ}$; and moreover, the first portion that came over had the exact density of the first.

A portion of this acid placed in a freezing mixture of ice and salt, suffered not the least solidification.

Tetra-Hydrate.-This hydrate was prepared in the same way as the first, namely, by preparing a quantity of colourless acid, ascertaining its saturating power, and mixing it with the proper quantity of distilled water, ascertained by calculation. It was then tried afterwards by saturation to see if it was correct; the numbers below will show the difference:Exp. Carb. of soda. Acid. Mean.

$\left.\begin{array}{l}\text { 1. . 29.96 }=30 \cdot 37 \\ 2 . .29 \cdot 87=30 \cdot 27\end{array}\right\} 30 \cdot 32$, or $60 \cdot 64$ per cent. real acid.

$$
\begin{aligned}
& \text { Real acid . 60.64 } \\
& \text { Water , } \frac{39 \cdot 36}{100 \cdot 00}
\end{aligned}
$$
Aecording to theory with 4 eqs. water. Real acid . . 60$$
\text { Water } \cdot \cdot \cdot \frac{40}{100}
$$ 
The acid had a density of 1.424 at $60^{\circ}$; it began to boil at $250^{\circ}$, and distilled over perfectly colourless and unchanged; towards the end, when slight decomposition commenced, the temperature rose to $260^{\circ}$.

Five or six ounces of very weak acid, of the density of $1 \cdot 180$, were introduced into a retort and kept heated just below its boiling-point for two or three hours; the heat was increased from time to time so as to make it boil briskly, and a thermometer introduced through the tubulure; when that which remained in the retort boiled uniformly at $250^{\circ}$, the heat was withdrawn and it was allowed to cool.

When the specific gravity of this acid was taken, it was found to be close upon that of the tetra-hydrate, but not exactly; probably if I had operated upon a large quantity, and carried it on for a longer time, it would have been more so; as found, its density was 1.412 instead of 1.424 , which would make a difference of rather less than $1 \frac{1}{2}$ per cent. deficiency in the acid.

This is, I have no doubt, the proper hydrate of nitric acid, $\mathrm{HO}, \mathrm{NO}_{5}+3 \mathrm{HO}$, as it is generally considered; and as Dr. Dalton correctly observed, acids which are either stronger or weaker than this acid, are brought to this strength by continued ebullition, the former losing acid and the latter water.

LXX. On the Products of the Decomposition of Cuminate of Ammonia by Heat. By Mr. Frederick FieLd*.

THE peculiar mode of decomposition which the ammonia 1 salts of inorganic acids exhibit when exposed to the action of heat, occurs likewise in the ammonia compounds of organic acids, although the results in the latter instances are usually of a more complicated nature. In most of these cases a formation of water takes place, the hydrogen of which is derived from the volatile alkali, while the acid furnishes the oxygen, the residue of which combines in a more intimate manner with the nitrogen of the ammonia. In decompositions, however, of inorganic compounds this reduction seems to be carried at once as far as it can go, the whole of the hydrogen contained in the ammonia being converted into water; while in organic salts this hydrogen is eliminated only by degrees, an intermediate body being produced between the original ammonia salt and the final product of the decomposition. Thus we find that nitrite and nitrate of ammonia, when exposed to heat, are at once converted into water, and respectively into nitrogen and nitrous oxide. Oxalate of ammonia, 1847. 